\title{
Süt Sığırlarında Vücut Kondisyon Skorunun (VKS) Belirlenmesi ve Sırt Yăg Kalınlığının Ölçülmesinde Ultrason Kullanımı
}

\author{
Rıdvan KOÇYİĞíT \\ Atatürk Üniversitesi Ziraat Fakültesi Zootekni Bölümü, Erzurum \\ (rkocyigit@atauni.edu.tr)
}

Geliş Tarihi :04.08.2016

Kabul Tarihi :16.03.2017

\begin{abstract}
ÖZET: Süt sığırlarında vücut kondisyon (VKS) skorunu belirlemek için, ineğin yağlanma durumu vücudun belli bölgelerinden gözle ve elle yoklanarak puanlanır. Bu sistemde; 1 skoru zayıf hayvanı, 5 skoru ise hayvanın çok yağlı olduğunu ifade etmektedir. Ancak son yıllarda VKS nin belirlenmesinde, belli frekanslardaki ses dalgalarıyla but-sırt yă̆ kalınlığını hassas ölçen ultrason cihazları kullanılmaktadır. Bu cihazlar yardımıyla süt sığırlarında yağ ve enerji rezervi tahmin edilerek, vücut kondisyonu daha doğru saptanabilmektedir. Bu derlemede süt sığırlarında vücut kondisyon skorunu belirleme yöntemleri ve sırt yağ kalınlığının
\end{abstract} ölçülmesinde ultrason kullanımı ele alınmıştır.

Anahtar kelimeler: Vücut kondüsyon skoru, ultrason, yağ kalınlığı, süt sığırı,

\section{Determination of Body Condition Score (BCS) for Dairy Cattle and Usage of Ultrasounds for Measurement of Back Fat Thicknes}

\begin{abstract}
The state of being fat is scored visually or by palpation of certain parts of the cow in order to determine body condition score (BCS) in dairy cattle. In this system, score 1 refers extremely thin animal, while score 5 implies obese animal. In recent years, ultrasounds which measure preciously fat thickness of back fat and rump fat by using sound waves in certain frequency are used. Fat and energy reserves are estimated by using these devices, and body condition scores are determined more preciously. In this review, methods for determination of body condition score as well as usage of ultrasound for measurement of the back fat thickness were investigated.
\end{abstract}

Key words: Body condition score, ultrasound, back fat thickness, dairy cattle

\section{GİRIS}

Başarılı ve karlı bir süt sı̆̆ırı yetiştiriciliği için bir inekten y1lda bir buzağı almak çok önemlidir. Çünkü süt sığırcılı̆̆ı işletmelerinin gelecekte var olmaları döl verimi ve süt üretim potansiyelinin devamlı ve etkin olarak kullanılabilmesine bağlıdır. Kondisyon skoru laktasyon dönemi boyunca sığırların enerji metabolizmasını gösteren ve aynı zamanda yem tüketimi ve süt verimi arasındaki ilişkiyi anlamaya yarayan iyi bir göstergedir (Janzekovic vd., 2015). Vücut kondisyon skoru düzenli aralıklarla çiftlik hayvanlarından alınarak değerlendirilen ve genel olarak kabul edilen bir tekniktir (Singh vd., 2015). Süt sığırlarında, vücut yağ rezervleri süt verimi, üreme kabiliyeti, yem tüketimi ve hayvanın sağlık durumu üzerinde önemli rol oynayan etkenlerdir (Jones, 1990; Waltner vd., 1993; Edmonson vd., 1989; Pedron vd., 1993).

Konuyla ilgili yürütülen araştırmalara göre yüksek süt verimi yönünde yapılan ıslah çalışmaları süt sığırlarının fertilite (üreme) ve sağlık sorunlarını artırmaktadır. Süt ineklerinde vücut kondisyonlarının belli dönemlerde saptanması üreme performans1, sağlık, süt verimi ile yakından ilişkili olan vücut enerji rezervlerinin takip edilerek sürü yönetiminin en uygun şekilde yapılmasına olanak sağlar. Sığırcılık işletmelerinde yıl boyunca yüksek süt verimi hedefine ulaşmak ve sürünün devamlılığ için ineklerin döl tutması gereklidir. Anılan hedefleri olan işletmelerde ineğin vücut yağı miktarı; süt üretimine, döl verimine, sığırın beslenmesine ve sağlı̆̆ında önemli bir etkiye sahiptir.

Yüksek süt verimli ineklerde buzağılamadan 24 ay sonra yani laktasyonun ilk dönemlerinde kuru madde tüketimi azalıren, süt veriminde bir artış meydana gelmekte bu durum, hayvanda negatif enerji dengesi durumu oluşturabilmektedir (Mishra vd., 2016). Vücut yağı depoları az veya yetersiz olan çok zayıf ineklerde laktasyonun başında süt üretimini destekleyecek yeterli vücut yağ rezervinin olmaması nedeniyle süt verimlerinde ciddi anlamda bir düşüş olabilmektedir. Ketosiz, abomasum yer değiştirmesi ve kızgınlığın sakin geçmesi gibi durumlar görülebilir. Diğer taraftan vücut yağ rezervleri aşırı yüksek bir başka ifadeyle yağlanmış ineklerde; güç doğum vb. sorunlar ortaya çıabilmektedir. Laktasyonun başlarında kuru madde tüketimini azaltan çeşitli yağlı inek sendromu ve ketosiz gibi metabolik hastalıklara yakalanma oranı yükselir, süt veriminde azalma görülür (Yaylak ve Kaya, 2000; Wattiaux, 1996). İleri üretim tekniklerini kullanan, bakım ve beslemeye özen gösteren ülkelerde, uygun olmayan vücut kondisyon skorunun fertilite de bir düşüşe yol açtığı bildirilmiştir (Richards vd., 1986; Loeffler vd., 1999; Moreira vd., 2000). Ancak baz1 araştırıcılar da vücut kondisyon skorunun döl verimi üzerine etkisinin olmadığını öne sürmüşlerdir. 
(Varışlı, 2008 Gillund vd., 2001; Ruegg and Milton, 1995; Waltner vd., 1993).

Sığırlarda vücut kondisyonuna göre sirt yağ kalınlığı, kondisyon skoru ve vücuttaki toplam yağ miktarı Çizelge 1'de verilmiştir ( Mishra vd., 2016; Çitil ve Uzlu, 2005).

Çizelge 1: Sığırın kondisyonuna göre vücut kondisyon skoru puanı, sırt yağ kalınlığı (mm) ve toplam yağ miktarı $(\mathrm{kg})$ değişimi.

\begin{tabular}{|l|c|c|c|}
\hline \multicolumn{1}{|c|}{ Sı̆̆̆ırın Kondisyonu } & VKS & Sırt Yağ Kalınlı̆̆ & Toplam Yă̆ Miktarı \\
\hline Aşırı derecede zayıf & 1 & $<5$ & $<50$ \\
\hline Çok Zayıf & 1.5 & 5 & 50 \\
\hline Zayıf & 2 & 10 & 76 \\
\hline Vasat (Kabul edilebilir) & 2.5 & 15 & 98 \\
\hline İyi & 3 & 20 & 122 \\
\hline Çok İyi & 3.5 & 25 & 146 \\
\hline Yağlı & 4 & 30 & 170 \\
\hline Çok Yağlı & 4.5 & 35 & 194 \\
\hline Aşırı Yağlı & 5 & $>35$ & $>194$ \\
\hline
\end{tabular}

Vücut Kondisyon Skorlarının (VKS)

\section{Belirlenmesinde Kullanılan Yöntemler}

İnekde vücut yă̆ rezervinin ultrasonla nesnel olarak ya da vücut kondisyon skoru ile öznel olarak tespit edilmesi süt ve döl veriminin etkinliğini artırmaya yardımcı olabilir.

Sığırlarda Vücut Kondisyon (VK) puanlaması, ineğin yağlanma durumunu tespit etmek için vücudun belli bölgelerde gözle ve palpasyon yöntemleriyle yapılabilir. Bunun için Şekil 1'de görüldüğü üzere hayvanın bel bölgesine el konularak parmaklar hafifçe bastırılarak processus transversus üzerindeki yă dokusu hissedilir ve vücut kondisyonu puanlanır (Canatan, 2013).

Süt 1rkı ineklerde puanlama sisteminde üçlük, dörtlük, yedilik ve dokuzluk skala sistemleri mevcut olup genel olarak beşlik skala üzerinden VKS belirlenmektedir (Serin, 2004).Vücut kondisyon (VK) puanlama sisteminde; 1 zayıf hayvanı, 5 skor puanı ise hayvanın çok yağlı olduğunu ifade etmektedir. Sığırlarda kondisyon puanlaması yapılırken $0.5^{\prime}$ lik ve $0,25^{\prime}$ lik ölçekler ile puanlama yapılabilmektedir. (Diler ve Aydın 2015; Diler, 2011; Varışlı ve Tekin, 2011). VKS düşük olan ineklerde bir sonraki laktasyonda beklenilen pik süt verimlerin gerçekleşmemesi ve sonuç olarak beklenen süt verimine ulaşamaması durumu söz konusu olabilmektedir. Vücut kondisyonu yüksek olan inekler çeşitli metabolik hastalıklara daha dirençsiz veya yatkın olurken vücut kondisyonu zayıf olan inekler gebe kalmama gibi problemlerle karşılaşabilmektedir. Söz konusu problemlerin olmaması veya önlenmesi için uygun olan vücut kondisyon skorunun belirlenip korunmas1 gerekmektedir.

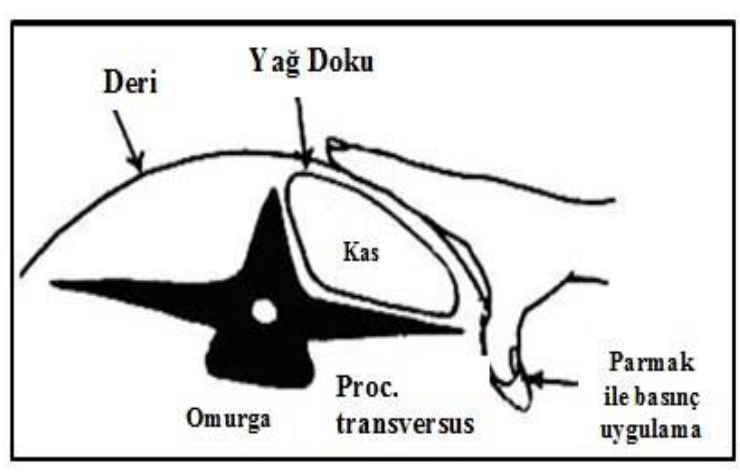

Şekil 1. Vücut kondisyon skorunun belirlenmesinde palpasyon yöntemi (Canatan, 2013).

\section{Sırt Yağ Kalınlığını Ölçmede Ultrason \\ Kullanımı}

Hayvanlarda genel olarak Ultrason kullanımı 1950'li yıllarda başlamış ve 1980'li yıllarda bilgisayar teknolojisinin gelişmesi ile birlikte bu teknik geliştirilerek B-mod ultrason, Real Time Ultrason, mobil (taşınabilir) cihazlar yardımıyla yăg ve kas miktarının ölçülmesine olanak sağlanmıştır ( Gökdal vd., 2004; Sabuncuoğlu, 2007). Sonraki süreçlerde ise ultrason ile ölçülüp elde edilen veriler değerlendirildiğinde karkas ölçüm ve miktarlarının tahmin edilmesinde daha doğru sonuçlar ve başarı elde edilmiştir (Sabuncuoğlu 2007).

Son yillarda VKS'nun belirlenmesinde kullanılmak üzere daha doğru ve gerçekçi, objektif sonuçlar verebilen ve sırt yağ kalınlığını ölçmek için belli frekanslardaki ses dalgalarıyla çalışabilen 
ultrasonlar geliştirilmiştir. Ultrasonik ölçümlerde deri altı kabuk yağı kalınlığ 1 tespit edilebilmektedir (Ayres vd., 2009). Vücut kondisyon skorunun (VKS) ile but-sırt yağ kalınlığı arasında ilişki olup, yüksek düzeyde bir korelasyon vardır.

Ultrason tekniğiyle sı̆̆ırlarda sırt bölgesinde yağ kalınlığını ölçmek için iki yöntem kullanılmaktadır. Bu metotlardan birincisi sırtta tuber coxae ile tuber ischiadicum arasına bir iğne batırmak suretiyle ultrason cihazıyla görüntü alınması yöntemidir. Ancak bu yöntemde hayvanın aşırı bir tepki vermesi nedeniyle genel olarak tercih edilmemektedir (Çitil ve Uzlu, 2005). Çizelge 2'de iğne metodu ile ölçülen sırt yağ kalınlığının VKS değeri olarak karşılığı verilmiştir.

Çizelge 2: İğne metodu ile ölçülen sırt yağ kalınlığının VKS değeri olarak karşılığ1 (Canatan, 2013).

\begin{tabular}{|l|l|}
\hline $\begin{array}{c}\text { Sırt Yă } \\
\text { Kalınlığı (mm) }\end{array}$ & \multicolumn{1}{c|}{$\begin{array}{c}\text { Vücut Kondisyon Skoru } \\
\text { (VKS) }\end{array}$} \\
\hline $5-10$ & 0 (Çok Kötü Kondisyon) \\
\hline $10-15$ & 1 (Kötü Kondisyon) \\
\hline $15-20$ & 2 (Orta Kondisyon) \\
\hline $20-25$ & 3 (İyi Kondisyon) \\
\hline $25-30$ & 4 (Çok İyi Kondisyon) \\
\hline$>30$ & 5 (Obez) \\
\hline
\end{tabular}

İkinci yöntem ise direkt olarak ultrasonografik olarak yağ ölçümünün cihaz vasıtasıyla yapılması esasına dayanmaktadır. Ultrason cihazı esas olarak A-modu ve B-modu olmak üzere iki tip ultrason geliştirilmiş olup bu modlardan A-modu ile lineer (doğrusal) yağ kalınlığı ölçülmekte ve B-modu ile de iki boyutlu ölçümlerden olan göz kası ölçümleri ve yağ alanı ölçülerek yetiştiricilikte kullanılmaktadır (Söbeli ve Kayaardı, 2014). Ölçümlerde kullanılan ultrasonografi cihazının sayılan bu özelliklere ilaveten aküyle (batarya, pil) çalışabilmesi, taşınabilir olması linear scanner $5-7 \mathrm{MHz}$ dalga boyu ve zoom özelliklerinin de olması önem arz etmektedir. $\mathrm{Bu}$ ölçümde tuber coxa ve tuber ischiadicum üst bölgelerine kadar olan sakral bölgesinin ölçülmesi ile sırt yă̆ kalınlığı bulunabilmektedir. Deri ile yağ tabakasında belirgin bir hat veya sınır olmadığı için ölçümlerde facia trunci profunda'ya olan kısım deri altı yağ dokusu olarak kabul edilebilir (Çitil ve Uzlu, 2005); Şekil 2 (Canatan, 2013; Schröder and Staufenbiel, 2006) ve Şekil 3'te (Schröder and Staufenbiel, 2006) süt sığırlarında ultrason ölçümlerinin alındıkları bölgeler verilmiştir. Ayrıca
Şekil 4, 5, 6 ve 7'de ultrason görüntüleme tekniğiyle alınmış resimler ve sırt yağ kalınlıkları da gösterilmiştir.

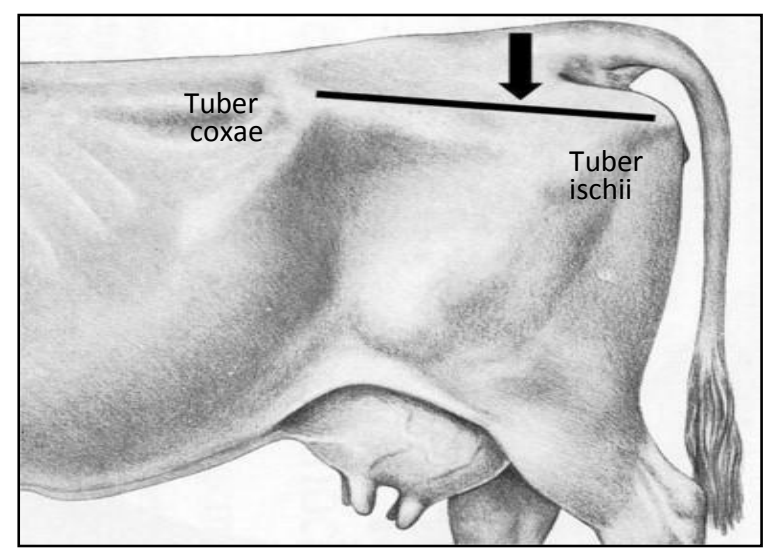

Şekil 2. Süt sı̆̆ırlarında ultrason ölçümlerinin alındığ 1 bölgelerin yandan görünüşü (Schröder and Staufenbiel, 2006).

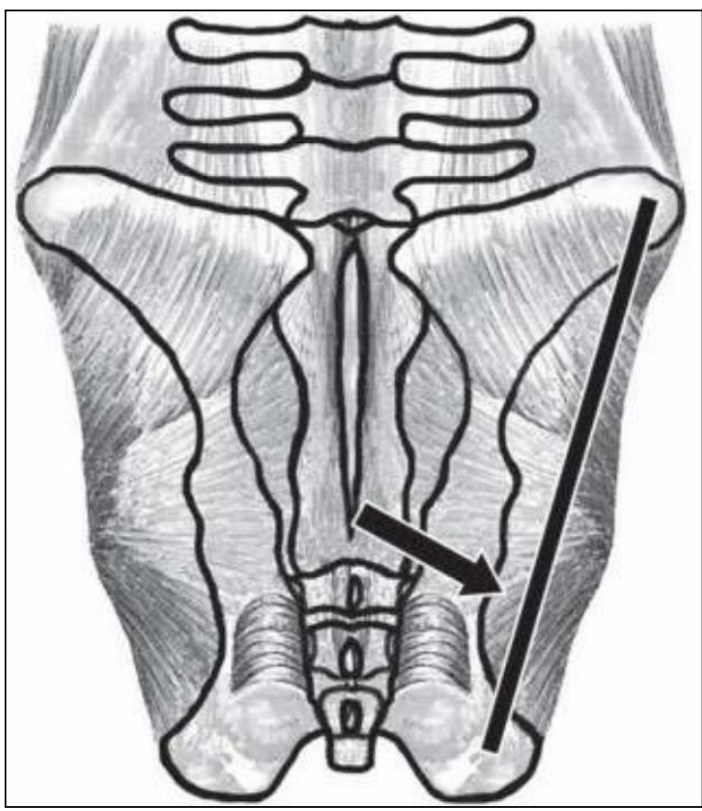

Şekil 3. Süt sığırlarında ultrason ölçümlerinin alındığ̣ bölgelerin üsten görünüşü (Schröder and Staufenbiel, 2006). 


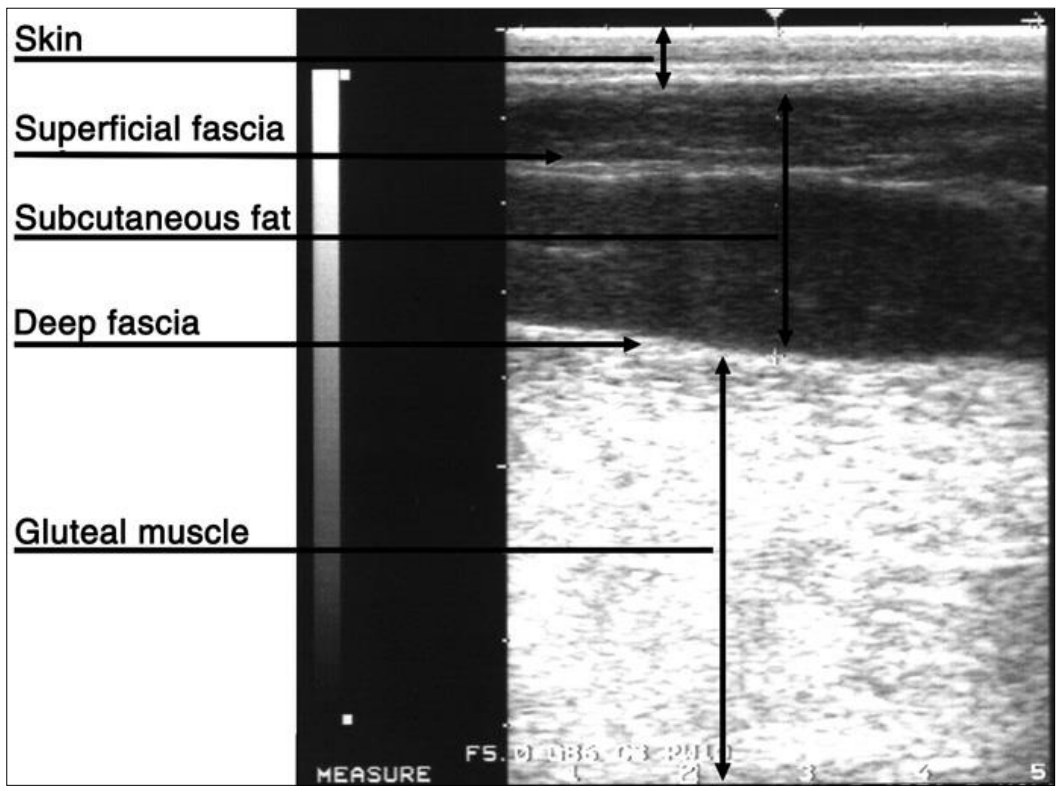

Şekil 4. Ultrason ile sacral bölgeden alınmış bir görüntü (sırt yağ kalınlı̆̆ 37 mm) (Hussein vd., 2013)

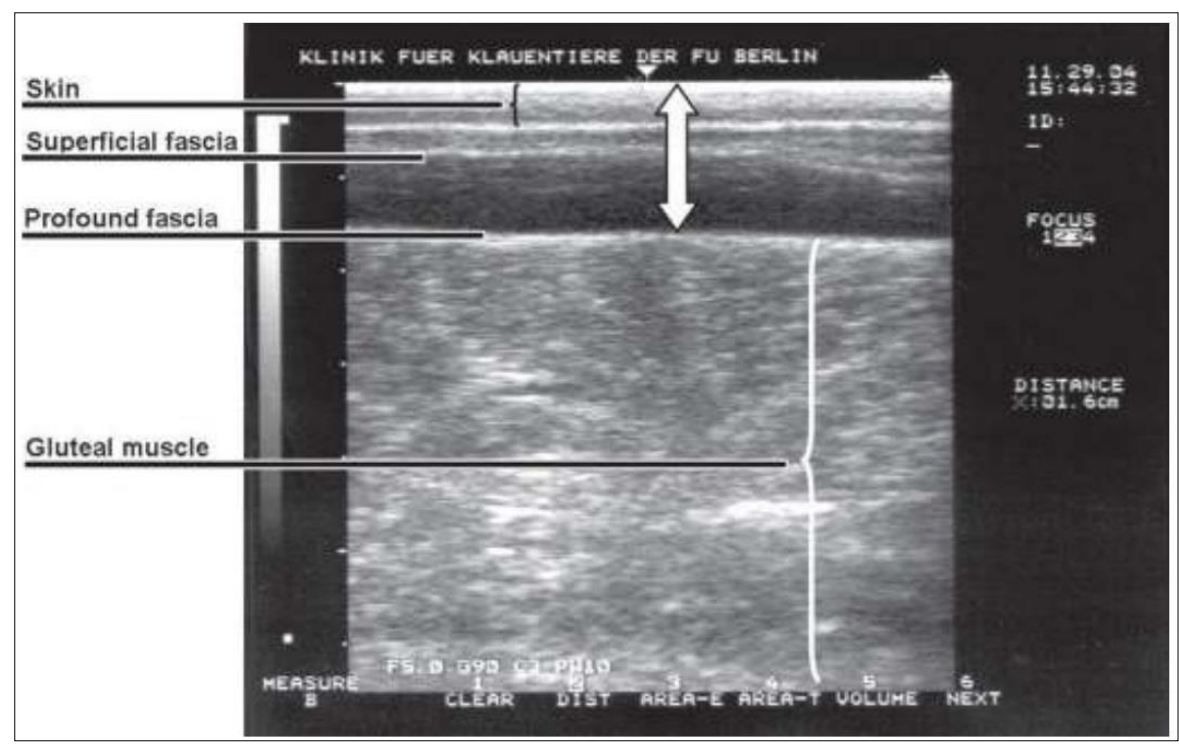

Şekil 5. Ultrason ile sacral bölgeden alınmış bir görüntü (sırt yağ kalınlığı $8 \mathrm{~mm}$ ) (Schröder and Staufenbiel, 2006). 


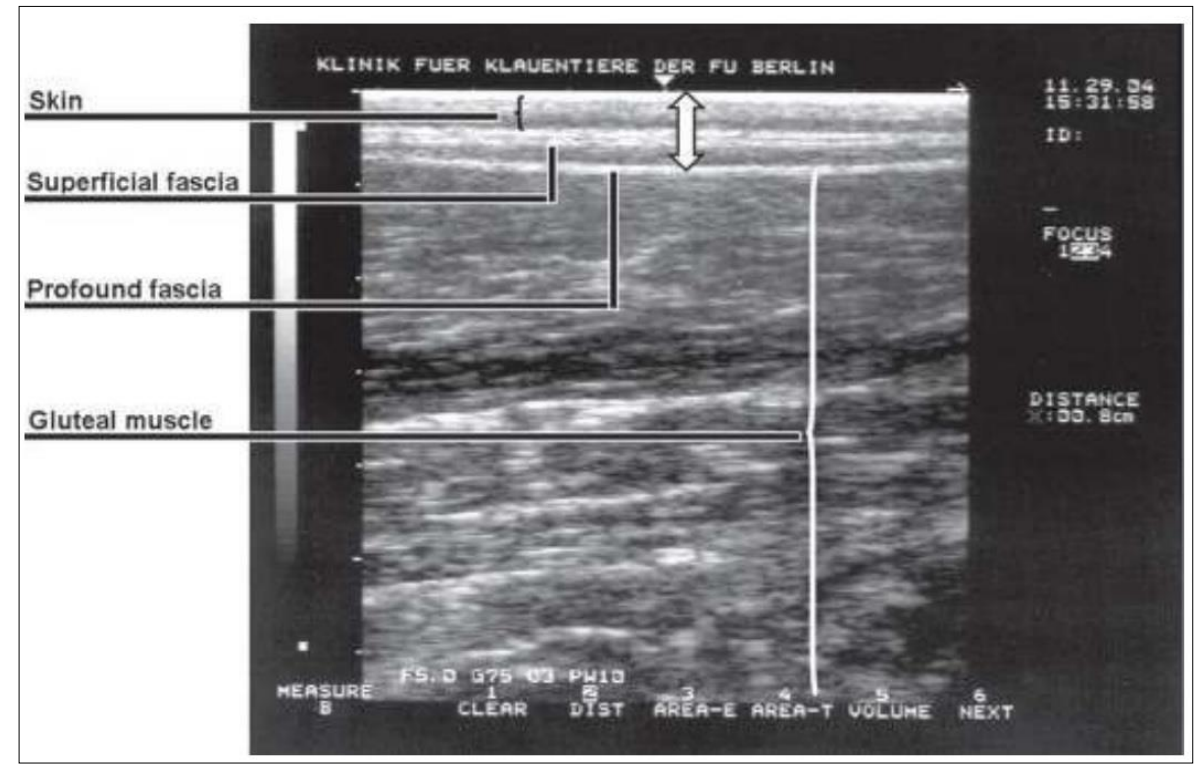

Şekil 6. Ultrason ile sacral bölgeden alınmış bir görüntü (sırt yağ kalınlığı 16 mm) (Schröder and Staufenbiel, 2006).

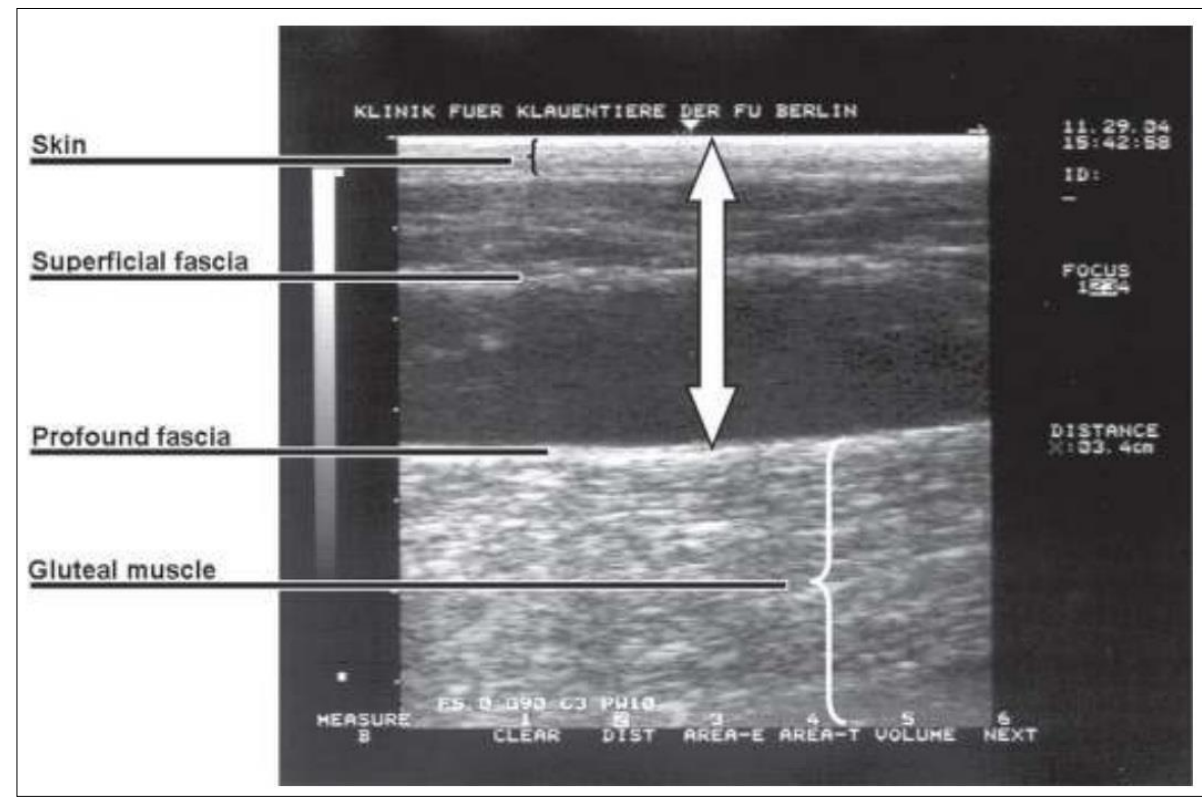

Şekil 7. Ultrason ile sacral bölgeden alınmış bir görüntü (sırt yağ kalınlı̆̆ 34 mm) (Schröder and Staufenbiel, 2006).

\section{SONUC}

Pratik olarak süt sığırı yetiștiriciliğinde VKS, süt üretiminin devamı ve hayvanın sağlık durumunu ortaya koyan önemli bir faktör olarak karşımıza çıkmaktadır. Çünkü doğum öncesi ve sonrası süreçlerde laktasyonun devamlılık düzeyi (persistensi) ve laktasyon eğrisinde meydana gelebilecek durumlar yine vücut kondisyon skoruyla yakından alakalıdır. Sırt yağ kalınlığının belirlenmesinde ultrason yönteminin kullanılması daha kolay ve kesin sonuçlar vermesi nedeniyle son yıllarda kullanımı artmaktadır. Modern işletmelerde 
bu uygulamanın düzenli olarak yapılması hayvanların farklı üretim dönemlerindeki kondisyon ve sağlıkları açısından önemli olup, süt sığırlarının farklı laktasyon dönemlerinde hayvanların kondisyon sinıflarına göre ayrılması ve bu sinıflara yemleme programlarının oluşturulmasına da iyi bir rehber olabileceği düşünülmektedir.

\section{KAYNAKLAR}

Ayres, H., Ferreira, R.M.,Torres-Junior, J.R., Demetrio,C.G.B., Lima, C.G.,Baruselli, P.S. 2009.Validasyon of body condition score as a predictor of subcutaneous fat in Nelore (Bos indicus) cows. Livestock Science.123,175-179.

Canatan, H. E.2013. İnek Ve Düvelerde Vücut Kondisyon Skoru Değișiminin Postpartum Döneme ve Fertilite Parametrelerine Etkisi. Ankara Üniversitesi Sağlık Bilimleri Enstitüsü. Ankara, Doktora Tezi, $171 \mathrm{~s}$.

Çitil, M., Uzlu, E., 2005. Sığırlarda doğum sonrası hastalıkların erken tanısında ultrasonografik yöntemle vücut kondisyon skor tayinin önemi. Kafkas Üniv. Vet. Fak. Derg. 11(2): 201-206.

Diler, A., 2011. Mikrobiyal Yem Katkı Maddesi ve Enzim Kombinasyonunun Esmer Sığırlarında Süt Verimi, Süt Kompozisyonu ve Vücut Kondisyon Skoru Üzerine Etkileri. Atatürk Üniversitesi, Fen Bilimleri Enstitüsü, Erzurum, Doktora Tezi, $69 \mathrm{~s}$

Diler, A., Aydın, R., 2015. Mikrobiyal yem katkı maddesi ve enzim kombinasyonunun esmer sığırlarda süt verimi, süt kompozisyonu ve vücut kondisyon skoru üzerine etkileri. Tekirdağ Ziraat Fakültesi Dergisi. 12 (1): 97-104.

Edmonson, A.J., I.J. Lean, L.D. Weaver, T. Farver, G. Webster., 1989. A body condition scoring chart for holstein dairy cows. J. Dairy Sci. 72:68-78

Gillund, P., Reksen, O., Grohn, Y.T., Karlberg, K., 2001. Body condition related to ketosis and reproductive performance in Norwegian dairy cows. J. Dairy Sci. 84:1390-1396.

Gökdal, Ö., Ülker, H., Karakuş, F., Temur, C., Handil, H., 2004. Erkek kuzularda karkas kompozisyonun tahmininde ultrason kullanımı: Yaş ve Genotip Etkileri. 4. Ulusal Zootekni Bilim Kongresi, 01-03 Eylül, Isparta, Türkiye.

Hussein, H.A., Westphal, A., R Staufenbiel, R., 2013. Relationship between body condition score and ultrasound measurement of backfat thickness in multiparous Holstein dairy cows at different production phases. Australian Veterinary Journal. 91(5): 185-189.

Janzekovic, M., Mocnik, U., Brus, M., 2015. Ultarasound Measurements for body condition score assessment of dairy cows. DAAAM İnternational Scientific Book. Chapter, 5158.

Jones, G. M., 1990. Body condition scores for evaluation of nutritional status. Virginia CooperativeExtension Service. Dairy Guidelines. Publication. 404-104.
Loeffler, S.H., De Vries M.J., Schukken, Y.H., De Zeeuw A.C., Dijkhuizen, A.A., Graaf F.M., Brand, A., 1999. Use of AI technician scores for body condition, uterine tone and uterine discharge in a model with disease and milk production parameters to predict pregnancy risk at first AI in Holstein dairy cows. Theriogenelogy. 51, 1267-1284.

Mishra, S., Kumari, K., Dubey, A., 2016. Body condition scoring of dairy cattle: A review. Research and Reviews: Journal of Veterinary Sciences. 2(1): 58-65.

Moreira, F., Risco, C., Pires, M.F.A., Ambrose, J.D., Drost, M., Delorenzo, M., Thatcher, W.W., 2000. Effect of body condition on reproductive efficiency of lactating dairy cows receiving a timed insemination. Theriogenology. 53: 13051309.

Pedron, O., Chell, F., Senator, E., Barolı, D., Rizza, R., 1993. Effect of body condition score at calving on performance, some blood parameters and milky fatty acit composition in dairy cows. J. Dairy Sci. 76: 2528-2535.

Richards, M.W., Spitzer, J.C., Werner, M.B., 1986. Effect of varying levels of postpartum nutrition and body condition at calving on subsequent reproductive performance in beef cattle. J. Anim. Sci. 62: 300-306.

Ruegg, P.L. and Milton, R.L., 1995. Body condition scores of Holstein cows on Prince Edward Island, Canada: Relationships with yield, reproductive performance, and disease. J. Dairy Sci. 78: 552-564.

Sabuncuoglu, N., 2007. Kesim hayvanlarında ultrason kullanımı. Atatürk Üniversitesi Ziraat Fakültesi Dergisi. 38(1): 189194.

Schröder, V., Staufenbiel, R., 2006. Invited Review: Methods to determine body fat reserves in the dairy cow with special regard to ultrasonographic measurement of back fat thickness J Dairy Sci. 89:1-14.

Serin, G., 2004. Sütçü ineklerde beden kondisyon skorunun reprodüktif performans üzerine etkisi. Kafkas Üniv. Vet. Fak. Derg. 10 (2): 221-225.

Singh, R., Randhawa, S. N. S. and Randhawa. C. S., 2015. Body condition score and its correlation with ultrasonographic back fat thickness in transition crossbred cows. Vet World. 8(3): 290-294.

Söbeli, C., Kayaardı, S. 2014. Et kalitesini belirlemede yeni teknikler. G1da. 39(4):251-258.

Varıșlı, Ö., Tekin, N.2011. Holştayn ineklerde vücut kondisyon skorunun fertilite ve bazı reprodüktif parametrelere etkisi. Ankara Ünv Vet. Fak Derg. 58 111-115.

Varışlı, Ö., 2008. Holştayn İneklerde Suni Tohumlamada Vücut Kondisyon Skorunun Fertilite Ve Reprodüktif Parametrelere Etkisi. Ankara Ünv. Sağlık Bilimleri Enstitüsü. Doktora Tezi, Ankara.

Waltner. S.S., J.P., Mcnamara and Hillers, J.K., 1993. Relationships of body condition score to production variables in high producing holstein dairy cattle. J.Dairy Sci. 76: 3410- 3419.

Wattiaux, M.A., 1996. Reproduction and Genetic Selection. The Babcock Institute University of Wisconsin 240 Agriculture Hall 1450 Linden Drive Madison WI 5370-1562 USA.

Yaylak, E., Kaya, A., 2000. süt sığırcılığında vücut kondisyon puanı ve önemi. Hayvansal Üretim. 41: 29-37. 